BMJ Open Sport \& Exercise Medicine

\title{
Effects of exercise on markers of oxidative stress: an Ancillary analysis of the Alberta Physical Activity and Breast Cancer Prevention Trial
}

\author{
Christine M Friedenreich, ${ }^{1,2}$ Vincent Pialoux, ${ }^{3}$ Qinggang Wang, ${ }^{1}$ Eileen Shaw, ${ }^{1}$ \\ Darren R Brenner, ${ }^{1,2}$ Xavier Waltz, ${ }^{4}$ Shannon M Conroy, ${ }^{5}$ Rhys Johnson, ${ }^{1}$ \\ Christy G Woolcott, ${ }^{6}$ Marc J Poulin, ${ }^{4}$ Kerry S Courneya ${ }^{7}$
}

To cite: Friedenreich CM, Pialoux V, Wang Q, et al. Effects of exercise on markers of oxidative stress: an Ancillary analysis of the Alberta Physical Activity and Breast Cancer Prevention Trial. BMJ Open Sport Exerc Med 2016;2:e000171. doi:10.1136/bmjsem-2016000171

- Prepublication history for this paper is available online. To view these files please visit the journal online (http://dx.doi.org/10.1136/ bmjsem-2016-000171).

Accepted 27 September 2016

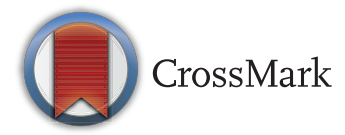

For numbered affiliations see end of article.

\section{Correspondence to} Dr Christine Friedenreich; christine.friedenreich@ albertahealthservices.ca

\section{ABSTRACT}

Background: 0xidative stress may contribute to cancer aetiology through several mechanisms involving damage to DNA, proteins and lipids leading to genetic mutations and genomic instability. The objective of this study was to determine the effects of aerobic exercise on markers of oxidative damage and antioxidant enzymes in postmenopausal women.

Methods: The Alberta Physical Activity and Breast Cancer Prevention Trial (ALPHA) was a two-centre, two-armed randomised trial of 320 inactive, healthy, postmenopausal women aged $50-74$ years.

Participants were randomly assigned to a year-long exercise intervention (225 min/week) or a control group while being asked to maintain a normal diet. Fasting blood samples were obtained and plasma concentrations of two oxidative damage markers (8-hydroxy-2'-deoxyguanosine (8-OHdG) and 8-isoprostaglandin F2 $\alpha$ (8-Iso-PGF2 $\alpha)$ ) and two antioxidant enzymes (superoxide dismutase and catalase) were measured at baseline, 6 months and 12 months. Intention-to-treat (ITT) and per-protocol analyses were performed using linear mixed models adjusted for baseline biomarker concentrations. A further exercise adherence analysis, based on mean minutes of exercise per week, was also performed.

Results: In the ITT and per-protocol analyses, the exercise intervention did not have any statistically significant effect on either oxidative damage biomarkers or antioxidant enzyme activity.

Conclusions: A year-long aerobic exercise intervention did not have a significant impact on oxidative stress in healthy, postmenopausal women.

Trial registration number: NCT00522262.

\section{INTRODUCTION}

Breast cancer is the most common cancer among women worldwide. ${ }^{1}{ }^{2}$ Since 2004 , breast cancer incidence rates have stabilised in North America. ${ }^{3}$ However, the absolute number of cases being diagnosed is still

\section{Summary box}

- This is the first large-scale randomised controlled trial of 320 postmenopausal women to examine the effect of a year-long aerobic exercise intervention on markers of oxidative damage and antioxidant enzyme activity.

- Overall, we did not observe any effect of physical activity on 8-hydroxy-2'-deoxyguanosine (8-OHdG), 8-isoprostaglandin F2 $\alpha$ (8-Iso-PGF2 $\alpha$ ), superoxide dismutase or catalase in this study.

- Oxidative stress may not be a predominant mechanism by which physical activity decreases breast cancer risk.

increasing because of population growth and ageing. ${ }^{1}$ Consistent epidemiological evidence exists that physical activity reduces postmenopausal breast cancer risk by 20-25\%. ${ }^{4}$ Several inter-related biological mechanisms are hypothesised to explain this association. ${ }^{4}$ Until now, five randomised controlled exercise trials have investigated the direct effect of exercise on hypothesised biomarkers of postmenopausal breast cancer. ${ }^{5-9}$ These studies have found that exercise decreases endogenous oestrogens, adiposity, leptin and markers of insulin resistance and inflammation. ${ }^{10-12}$

Systemic oxidative stress has been implicated in many diseases and disorders, including the pathogenesis and progression of breast cancer. ${ }^{13-15}$ Oxidative stress refers to the excessive production of reactive oxygen species (ROS), particularly from oxygen radicals, during a period of increased exposure to environmental stress. ROS are a normal by-product of metabolism and are necessary components of both cell signalling and homoeostasis; ${ }^{16}$ however, their presence 
in excess amounts can have a negative physiological effect. ROS can induce damage to lipids, proteins and DNA, in turn leading to genetic mutations and genomic instability, thus contributing to carcinogenesis. ${ }^{17}$ In addition, ROS have been shown to be involved in the signalling pathways of neoangiogenesis, a mechanism that aids tumour growth and metastasis development. ${ }^{18}$

The balance of oxidative stress factors is mainly determined by endogenous enzymatic mechanisms, although exogenous lifestyle factors such as dietary intake, physical activity and medication use also play a major role. ${ }^{19}{ }^{20} \mathrm{~A}$ single bout of intense exercise causes a transient increase in ROS. ${ }^{16}$ However, as part of a favourable biological adaptive response referred to as the 'exercise-induced oxidative stress paradox', ${ }^{21}$ exercise training enhances antioxidant and oxidative damage repair enzyme capacity, ${ }^{22}{ }^{23}$ and subsequently reduces overall oxidative damage. ${ }^{24}$ Enzymatic antioxidants may decrease breast cancer development by neutralising the over-generated ROS. ${ }^{26}$ Hence, antioxidant enzymes such as superoxide dismutase (SOD) and catalase (CAT) are established markers for assessing the beneficial effect of physical training on antioxidant status. ${ }^{25} 27$ It is also hypothesised that oxidative damage markers can be affected by physical exercise training through the enhanced activity of DNA damage repair mechanisms. ${ }^{28}$ These include: 8-hydroxy-2'-deoxyguanosine (8-OHdG), an accurate marker of DNA oxidation that is associated with breast cancer risk, ${ }^{29} 30$ and 8-isoprostaglandin $\mathrm{F} 2 \alpha$ (8-Iso-PGF2 $\alpha$ ), a lipid peroxidation product that is a reliable marker of in vivo oxidative stress and is also related to breast cancer risk. ${ }^{31}$

Until now, very few studies conducted in humans have examined the effect of long-term exercise on markers of oxidative stress. Of those studies, most did not focus on cancer-free, previously inactive, postmenopausal women who are of greatest relevance to postmenopausal breast cancer risk. One randomised controlled trial did examine the effects of a year-long exercise intervention on oxidative stress in postmenopausal women, but investigated only one biomarker via urine, F2-isoprostane. ${ }^{24}$ To the best of our knowledge, no other randomised controlled trials conducted in humans have studied the effects of long-term exercise on accurate and reliable markers of DNA oxidation, lipid peroxidation and antioxidant enzyme levels. The Alberta Physical Activity and Breast Cancer Prevention (ALPHA) Trial was a randomised controlled trial that examined how a 1 year aerobic exercise intervention influenced hypothesised biomarkers that can modulate risk of postmenopausal breast cancer compared to a sedentary lifestyle. ${ }^{6}$ This analysis uses data from the ALPHA Trial to describe the effects of a year-long, moderate-to-vigorous intensity, aerobic (225 $\mathrm{min} /$ week) exercise intervention on the oxidative stress markers SOD, CAT, 8-iso-PGF2 $\alpha$ and 8 -OHdG, which were secondary outcomes from the ALPHA Trial.

\section{METHODS}

\section{Study population}

Methods for the ALPHA Trial have been previously reported. ${ }^{6}$ Briefly, women were recruited from May 2003 to June 2005 through targeted mailings to participants in the Alberta Breast Screening Programme, brochures distributed to family physicians and not currently undertaking or planning to undertake a weight loss programme, through media campaigns in Calgary and Edmonton, Alberta. Specific eligibility criteria included: inactive women $(<90 \mathrm{~min} /$ week recreational activity over the past year or, if between 90 and $120 \mathrm{~min} /$ week of physical activity had a $\mathrm{VO}_{2} \max <34.5 \mathrm{~mL} / \mathrm{kg} / \mathrm{min}$ ); aged 50-74 years; postmenopausal for at least 24 months; no previous cancer diagnosis besides non-melanoma skin cancer; no major comorbidities; acceptable heart and lung function as assessed by baseline fitness test; physician clearance for unrestricted physical activity; normal fasting lipids, glucose thyroid stimulating hormone and alanine aminotransferase; body mass index (BMI) 22$40 \mathrm{~kg} / \mathrm{m}^{2}$; non-smoker; <14 drinks of alcohol/week; without diabetes; breast tissue density greater than a zero density level; no medications or exogenous hormones that might influence oestrogen metabolism; not currently or planning to undertake a weight loss programme and no planned, extended absences in the 18 months subsequent to enrolment.

\section{Intervention}

Women were randomised to either a year-long, moderate-to-vigorous intensity aerobic exercise intervention of $225 \mathrm{~min} /$ week $(\mathrm{n}=160)$ or to a control group that was asked to maintain their current activity levels $(n=160)$. The final exercise prescription was 45 min long sessions, five times per week at $70-80 \%$ heart rate reserve for 1 year. Of these sessions, at least three were facility-based with on-site exercise trainers while the remaining sessions were home based. The initial exercise prescription of three weekly sessions of 15-20 min duration at an intensity of $50-60 \%$ heart rate reserve was gradually increased over a period of 3 months to the final prescription. To monitor heart rate, participants wore Polar A3 heart rate monitors throughout the exercise period. Participants in both groups were also asked not to alter their diet for the duration of the study. Ethics approval was obtained from ethics review boards of the University of Calgary, the University of Alberta and the Alberta Cancer Board and each participant provided written informed consent.

\section{Blood collection and biomarker assays}

Fasting blood was collected at baseline $(60 \mathrm{~mL}), 6$ and 12 months $(40 \mathrm{~mL})$ after a minimum 10 hours fast. Participants were instructed not to exercise or consume alcohol within 24 hours of the test. All blood samples were collected, processed and stored within 4 hours of collection at $-86^{\circ} \mathrm{C}$ at the Holy Cross Centre in Calgary until the time of the assays. The laboratory assays 
described below were carried out at the University of Calgary with the oversight of VP (Lyon). All three samples for each participant were included in a single batch with equal numbers of samples from exercisers and controls and two pooled quality control samples. Samples were randomly allocated within each plate. Laboratory personnel were blinded to the samples. All samples were assayed in duplicate. For any sample, if the within-individual CV between repeats was above 20\%, we used the value that was closest to the mean concentration for the plate. Values above four SDs from the mean of each plate were defined as outliers and removed. Values below the limit of detection (ie, below the optical density of the negative control) were removed from analyses for each assay. In order to adjust for potential plate effects, concentration values were adjusted for the overall within-plate mean concentrations.

Plasma 8-OHdG and 8-Iso-PGF2 $\alpha$ were measured using ELISA kits (Cell Biolabs, San Diego, California, USA). ${ }^{23}$ Detection limits, intra-assay and interassay coefficients of variation $(\mathrm{CV})$ were $0.1 \mathrm{ng} / \mathrm{mL}, 5 \%$ and $5 \%$, respectively, for $8-\mathrm{OHdG}$ and $0.1 \mathrm{ng} / \mathrm{mL}$ and $6 \%$ and $6 \%$, respectively, for 8 -iso-PGF2 $\alpha$. The quantity of $8-\mathrm{OHdG}$ and 8-iso-PGF2 $\alpha$ was determined by comparing its absorbance at $450 \mathrm{~nm}$ in a sample with those of a standard curve using an M2e SpectraMax microplate reader.

Plasma CAT and SOD activity were measured spectrophotometrically using standard quantification methods. ${ }^{33}$ Catalase activity was quantified by the method of Johansson and Borg using hydrogen peroxide as a substrate and formaldehyde as a standard. ${ }^{34}$ SOD activity was quantified using the Beauchamp and Fridovich method, ${ }^{35}$ slightly modified by Oberley and Spitz. ${ }^{36}$ The intra-assay and interassay CVs were $5 \%$ and $12 \%$, respectively, for catalase and $6 \%$ and $7 \%$, respectively, for SOD.

\section{Statistical methods}

All biomarker levels were subjected to log-transformation to obtain an approximately symmetrical distribution after observing data to be askew. The primary ITT analysis included all values that were available at each study interval. The per-protocol analysis included all control group participants and only those in the exercise group who completed $\geq 90 \%$ of the exercise prescription $(\geq 204 \mathrm{~min} /$ week) for weeks 13-52 of the exercise intervention (excluding the 12-week ramp-up period). A further analysis was performed based on exercise adherence, using mean minutes of activity per week for all 52 weeks of the study. Exercise adherence was classified into the following categories based on previously defined public health guidelines: $<150,150-225$ and $>225 \mathrm{~min} /$ week. $^{37}$

General linear mixed models were used for all biomarkers to observe the intervention effects using the measures at 6 and 12 months as repeated measurers. These models included the main effects of intervention and time, as well as their interaction term, and were adjusted for baseline values of each biomarker. Treatment effect ratios (TERs) were estimated as a geometric mean ratio of the exercisers compared to the controls from the linear mixed models. A TER > 1.0 indicates higher oxidative stress biomarker or antioxidant enzyme activity levels among exercisers compared to controls.

The secondary analysis examined if the effect of exercise on the biomarkers of interest was mediated by exercise adherence, changes in body composition (assessed by BMI, body fat percentage and intra-abdominal fat area), overall physical fitness throughout the study, (assessed by $\mathrm{VO}_{2} \max$ ) and diet or vitamin intake. Effect modification (moderation) was evaluated based on statistical significance of the interaction term $\left(\mathrm{P}_{\text {heterogeneity }}\right)$ between the intervention group assignment and each proposed moderator at baseline in the ITT analysis models. ${ }^{38}$ Hypothesised moderators included baseline levels of: fitness $\left(\mathrm{VO}_{2} \mathrm{max}\right)$, age, BMI, body fat percentage, intra-abdominal fat area and oxidative stress biomarkers or antioxidant enzyme activity. All statistical analyses completed for this study were performed with the use of SAS software (V.9.2; SAS Institute, Cary, North Carolina, USA).

\section{RESULTS}

Of the 320 women initially randomised, 311 (97\%) completed the trial. Baseline characteristics of the study population have previously been described. ${ }^{6}$ At baseline, there were limited differences between the exercise and control groups with respect to baseline concentrations of the biomarkers of interest (table 1).

In the ITT analysis of the data (table 2), we did not observe any statistically significant differences in levels for the oxidative stress biomarkers or antioxidant enzyme activities between the two groups. Similarly, in the per-protocol analysis (table 3), no biomarkers showed a statistically significant difference between groups following the intervention.

In the exercise adherence analysis (table 4), no differences were observed in these biomarker levels between any levels of exercise adherence compared to the control group. Finally, we did not observe any statistically significant mediation or effect modification by fitness $\left(\mathrm{VO}_{2} \mathrm{max}\right)$ age, BMI, body fat percentage, intra-abdominal fat area and oxidative stress biomarkers or antioxidant enzyme activity.

\section{DISCUSSION}

Our year-long moderate-to-vigorous intensity exercise intervention among previously inactive, postmenopausal, cancer-free women did not cause any statistically significant effects compared to the controls for biomarkers of oxidative stress or antioxidant enzyme activity.

Oxidative stress is one of the more recently hypothesised mechanisms whereby physical activity can influence the risk of breast cancer and other chronic diseases. While there have been a limited number of studies in this area of research, the findings of this trial differ from 
Table 1 Baseline characteristics of study participants, the Alberta physical activity and breast cancer prevention trial, 2003-2007, $n=320$

\begin{tabular}{|c|c|c|}
\hline $\begin{array}{l}\text { Baseline } \\
\text { characteristic }\end{array}$ & $\begin{array}{l}\text { Exercisers } \\
(n=160) \\
\text { Mean } \pm S D\end{array}$ & $\begin{array}{l}\text { Controls } \\
(n=160) \\
\text { Mean } \pm S D\end{array}$ \\
\hline Age (years) & $61.2 \pm 5.4$ & $60.6 \pm 5.7$ \\
\hline \multicolumn{3}{|c|}{ Body composition measurements } \\
\hline $\operatorname{BMI}\left(\mathrm{kg} / \mathrm{m}^{2}\right)$ & $29.1 \pm 4.5$ & $29.2 \pm 4.3$ \\
\hline $\begin{array}{l}\text { Intra-abdominal fat } \\
\text { area }\left(\mathrm{cm}^{2}\right)\end{array}$ & $101.4 \pm 55.4$ & $103.2 \pm 56.0$ \\
\hline Total body fat $(\mathrm{kg})$ & $30.9 \pm 8.2$ & $31.3 \pm 8.6$ \\
\hline Per cent body fat & $42.2 \pm 4.9$ & $42.4 \pm 5.7$ \\
\hline $\begin{array}{l}\text { Total energy intake } \\
\text { (kcal/day) }\end{array}$ & $1551.2 \pm 598.7$ & $1527.3 \pm 535.0$ \\
\hline \multicolumn{3}{|c|}{ Past year total physical activity (MET -hours/week) } \\
\hline $\begin{array}{l}\text { Total physical } \\
\text { activity }\end{array}$ & $114.2 \pm 57.6$ & $129.1 \pm 77.9$ \\
\hline $\begin{array}{l}\text { Occupational } \\
\text { activity }\end{array}$ & $50.4 \pm 49.1$ & $52.2 \pm 57.9$ \\
\hline Household activity & $52.9 \pm 34.3$ & $63.9 \pm 53.5$ \\
\hline Recreation activity & $10.2 \pm 11.8$ & $12.1 \pm 13.6$ \\
\hline \multirow{2}{*}{$\begin{array}{l}\text { Maximal oxygen } \\
\text { consumption } \\
\text { (mL/kg/min) }\end{array}$} & $27.1 \pm 6.2$ & $26.8 \pm 6.0$ \\
\hline & Median (IQR) & Median (IQR) \\
\hline$\overline{S O D}$ & $12.6(11.1-14.1)$ & $12.5(11.3-13.8)$ \\
\hline CAT & $21.0(13.6-30.9)$ & $19.8(13.0-29.0)$ \\
\hline 8-iso-PGF2 $\alpha$ & $246(206-293)$ & $258(201-295)$ \\
\hline 8-OHdG & $7.3(6.2-8.0)$ & $7.2(6.4-7.9)$ \\
\hline
\end{tabular}

previous research. Exercise has generally been found to increase antioxidant enzyme capacity while decreasing lipid peroxidation and DNA damage markers in healthy populations of men and women. ${ }^{39-51}$ However, not all studies showed consistency across biomarkers, ${ }^{40} 42454652$ and some studies have shown no effect of exercise on oxidative stress or antioxidant capacity. ${ }^{53}$ In these findings, study designs and populations are heterogeneous. Very few randomised controlled studies have examined these markers of oxidative stress in inactive, postmenopausal women and none considered all of the above markers simultaneously. Of these studies, most have shown a beneficial impact of physical activity in reducing level of oxidative stress or increasing antioxidant enzyme activity, ${ }^{24}{ }^{52}{ }^{55-59}$ but not all are consistent. ${ }^{56}$ Only one trial was comparable to the ALPHA Trial in terms of size, duration and scope. ${ }^{10}$ While this study showed a non-statistically significant decrease in urinary F2-isoprostane, no antioxidant enzymes were assayed.

The role of physical activity, specifically exercise training, has been attributed to increased antioxidant capacity and decreased oxidative stress biomarkers in what has been described as the 'oxidative stress paradox'. ${ }^{21}$ When exercise is performed, ROS concentrations

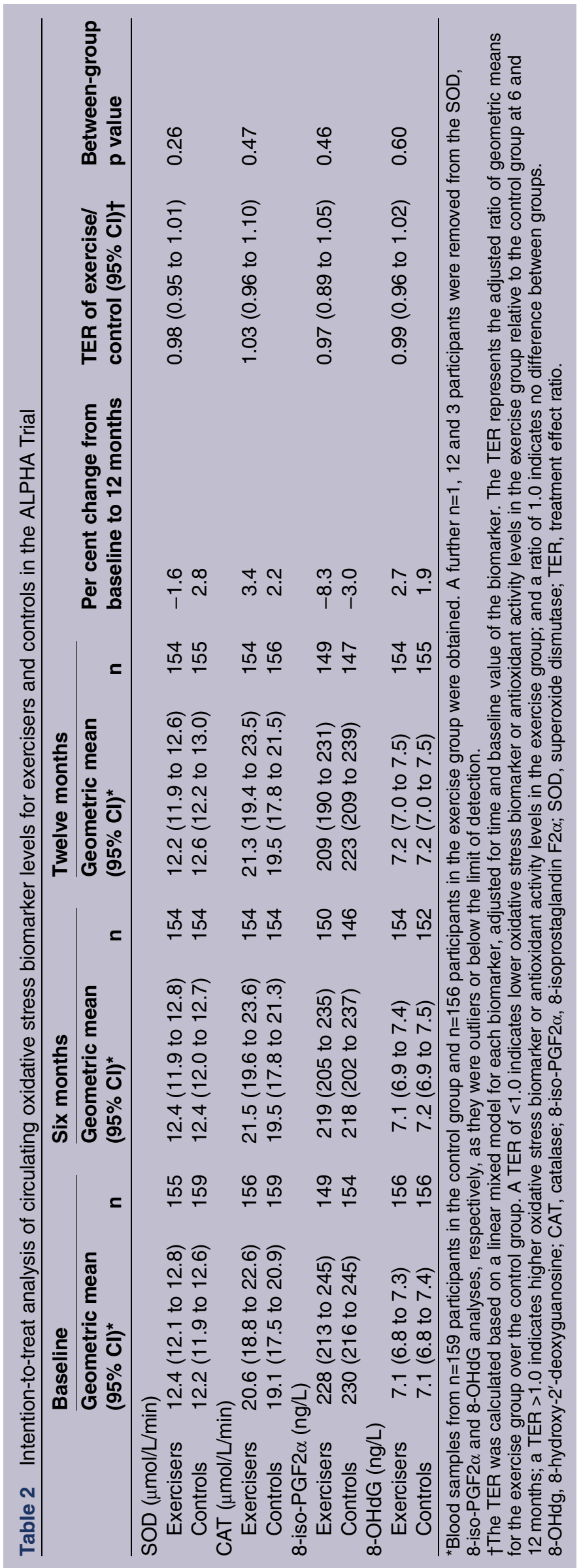




\begin{tabular}{|c|c|c|c|c|c|c|c|c|c|}
\hline & \multicolumn{2}{|l|}{ Baseline } & \multicolumn{2}{|l|}{ Six months } & \multicolumn{2}{|l|}{ Twelve months } & \multirow[b]{2}{*}{$\begin{array}{l}\text { Per cent change from } \\
\text { baseline to } 12 \text { months }\end{array}$} & \multirow[b]{2}{*}{$\begin{array}{l}\text { TER of exercise/ } \\
\text { control }(95 \% \mathrm{CI}) \ddagger\end{array}$} & \multirow[b]{2}{*}{$\begin{array}{l}\text { Between-group } \\
p \text { value }\end{array}$} \\
\hline & $\begin{array}{l}\text { Geometric mean } \\
(95 \% \mathrm{Cl}) \dagger\end{array}$ & $\mathbf{n}$ & $\begin{array}{l}\text { Geometric mean } \\
(95 \% \mathrm{Cl}) \dagger\end{array}$ & $\mathbf{n}$ & $\begin{array}{l}\text { Geometric mean } \\
(95 \% \mathrm{Cl}) \dagger\end{array}$ & $\mathbf{n}$ & & & \\
\hline \multicolumn{10}{|c|}{$\mathrm{SOD}(\mu \mathrm{mol} / \mathrm{L} / \mathrm{min})$} \\
\hline Exercisers & $12.3(11.8$ to 12.7$)$ & 91 & $12.3(11.7$ to 12.9$)$ & 92 & $12.2(11.8$ to 12.6$)$ & 92 & -0.3 & \multirow[t]{2}{*}{0.98 (0.94 to 1.02$)$} & \multirow[t]{2}{*}{0.30} \\
\hline Controls & $12.2(11.9$ to 12.6$)$ & 159 & $12.4(12.0$ to 12.7$)$ & 154 & $12.6(12.2$ to 13.0$)$ & 155 & 2.8 & & \\
\hline \multicolumn{10}{|c|}{ CAT $(\mu \mathrm{mol} / \mathrm{L} / \mathrm{min})$} \\
\hline Exercisers & $21.5(19.2$ to 24.0$)$ & 92 & 21.3 (18.8 to 24.2$)$ & 92 & 21.6 (19.1 to 24.4$)$ & 92 & 1.4 & \multirow[t]{2}{*}{1.00 (0.92 to 1.09$)$} & \multirow[t]{2}{*}{0.99} \\
\hline Controls & 19.1 (17.5 to 20.9$)$ & 159 & 19.5 (17.8 to 21.3$)$ & 154 & 19.5 (17.8 to 21.5$)$ & 156 & 2.2 & & \\
\hline \multicolumn{10}{|c|}{ 8-iso-PGF2 $\alpha$ (ng/L) } \\
\hline Exercisers & 220 (199 to 244$)$ & 88 & 224 (207 to 242) & 91 & 212 (188 to 240$)$ & 89 & -3.7 & \multirow[t]{2}{*}{0.98 (0.90 to 1.08$)$} & \multirow[t]{2}{*}{0.89} \\
\hline Controls & 230 (216 to 245$)$ & 154 & 218 (202 to 237$)$ & 146 & 223 (209 to 239) & 147 & -3.0 & & \\
\hline \multicolumn{10}{|c|}{$8-\mathrm{OHdG}(\mathrm{ng} / \mathrm{L})$} \\
\hline Exercisers & $7.2(6.9$ to 7.5$)$ & 92 & $7.2(6.9$ to 7.5$)$ & 92 & $7.3(7.1$ to 7.6$)$ & 92 & 1.6 & \multirow[t]{2}{*}{0.99 (0.95 to 1.02$)$} & \multirow[t]{2}{*}{0.44} \\
\hline Controls & 7.1 (6.8 to 7.4$)$ & 156 & $7.2(6.9$ to 7.5$)$ & 152 & $7.2(7.0$ to 7.5$)$ & 155 & 1.9 & & \\
\hline \multicolumn{10}{|c|}{$\begin{array}{l}\text { *Per-protocol analysis included all participants in the control group and only those participants who fulfilled } \geq 90 \% \text { of the exercise prescription over weeks } 13-52 \text { of the study. } \\
\text { †Blood samples from } n=159 \text { participants in the control group and } n=156 \text { participants in the exercise group were obtained. A further } n=1,12 \text { and } 3 \text { participants were removed from the SOD, } \\
\text { 8-iso-PGF2 } \alpha \text { and } 8-O H d G \text { analyses, respectively, as they were outliers or below the limit of detection. } \\
\text { fThe TER was calculated based on a linear mixed model for each biomarker, adjusted for time and baseline values of the biomarker. The TER represents the adjusted ratio of geometric means } \\
\text { for the exercise group over the control group. A TER of }<1.0 \text { indicates lower oxidative stress biomarker or antioxidant activity levels in the exercise group relative to the control group at } 6 \text { and } \\
12 \text { months; a TER }>1.0 \text { indicates higher oxidative stress biomarker or antioxidant activity levels in the exercise group; and a ratio of } 1.0 \text { indicates no difference between groups. } \\
\text { 8-iso-PGF2 } \alpha, 8 \text {-isoprostaglandin F2 } \alpha ; 8-O H d g, 8 \text {-hydroxy-2'-deoxyguanosine; CAT, catalase; SOD, superoxide dismutase; TER, treatment effect ratio. }\end{array}$} \\
\hline
\end{tabular}


Table 4 Adherence level ${ }^{*}$ analyses of oxidative stress biomarker levels at baseline and 12 months in exercisers and controls in the ALPHA Tria

\begin{tabular}{|c|c|c|c|c|c|c|c|}
\hline & $\begin{array}{l}\text { Baseline } \\
\text { Geometric mean } \\
(95 \% \mathrm{Cl}) \dagger\end{array}$ & $\begin{array}{l}\text { Twelve months } \\
\text { Geometric mean } \\
(95 \% \mathrm{Cl}) \dagger\end{array}$ & $\mathbf{n}$ & $\begin{array}{l}\text { Ratio } 12 \text { months/baseline } \\
\text { (95\% Cl) } \neq\end{array}$ & Per cent change§ & p Valueף & $P_{\text {trend }}{ }^{\star \star}$ \\
\hline \multicolumn{8}{|l|}{$\mathrm{SOD}(\mu \mathrm{mol} / \mathrm{L} / \mathrm{min})$} \\
\hline Controls & $12.2(11.9$ to 12.6$)$ & 12.6 (12.2 to 13.0$)$ & 155 & $1.02(1.00$ to 1.05$)$ & 2.5 & Ref. & 0.26 \\
\hline$<150 \mathrm{~min} /$ week & $12.7(12.1$ to 13.3$)$ & 12.1 (11.4 to 12.9$)$ & 40 & 0.98 (0.92 to 1.03$)$ & -2.5 & 0.11 & \\
\hline 150-225 min/week & 12.5 (11.9 to 13.0$)$ & $12.2(11.8$ to 12.7$)$ & 66 & $0.99(0.95$ to 1.03$)$ & -1.1 & 0.17 & \\
\hline >225 min/week & $12.0(11.3$ to 12.6$)$ & 12.3 (11.7 to 12.8$)$ & 47 & 1.01 (0.96 to 1.06$)$ & 0.6 & 0.54 & \\
\hline \multicolumn{8}{|l|}{ CAT $(\mu \mathrm{mol} / \mathrm{L} / \mathrm{min})$} \\
\hline Controls & $18.9(17.4$ to 20.7$)$ & 19.5 (17.8 to 21.4 ) & 156 & 1.02 (0.96 to 1.09$)$ & 2.1 & Ref. & 0.98 \\
\hline$<150 \mathrm{~min} /$ week & 21.2 (17.4 to 25.9$)$ & $23.3(19.2$ to 28.5$)$ & 40 & $1.12(0.99$ to 1.28$)$ & 12.4 & 0.19 & \\
\hline 150-225 min/week & 19.4 (16.8 to 22.5$)$ & 19.4 (16.7 to 22.6$)$ & 67 & $0.99(0.90$ to 1.10$)$ & -0.8 & 0.63 & \\
\hline$>225 \mathrm{~min} /$ week & $22.0(19.1$ to 25.3$)$ & $22.5(19.1$ to 26.5$)$ & 47 & $1.05(0.93$ to 1.18$)$ & 4.5 & 0.74 & \\
\hline \multicolumn{8}{|l|}{ 8-OHdG (ng/L) } \\
\hline Controls & 7.1 (6.8 to 7.3$)$ & $7.2(7.0$ to 7.5$)$ & 153 & $1.03(1.00$ to 1.05$)$ & 2.8 & Ref. & 0.78 \\
\hline$<150 \mathrm{~min} /$ week & 6.7 (6.2 to 7.1$)$ & 7.0 (6.4 to 7.5$)$ & 40 & 1.03 (0.98 to 1.08$)$ & -2.5 & 0.96 & \\
\hline 150-225 min/week & $7.2(6.9$ to 7.5$)$ & 7.4 (7.0 to 7.7$)$ & 67 & $1.03(0.99$ to 1.07$)$ & -1.1 & 0.98 & \\
\hline$>225 \mathrm{~min} /$ week & 7.2 (6.8 to 7.7$)$ & 7.3 (7.0 to 7.7$)$ & 47 & 1.02 (0.97 to 1.07$)$ & 0.6 & 0.71 & \\
\hline \multicolumn{8}{|l|}{ 8-iso-PGF2 $\alpha$ (ng/L) } \\
\hline Controls & 234 (220 to 250$)$ & 223 (209 to 239 ) & 143 & 0.97 (0.89 to 1.05$)$ & -3.2 & Ref. & 0.77 \\
\hline$<150 \mathrm{~min} /$ week & 240 (216 to 267$)$ & 197 (156 to 249$)$ & 38 & 0.85 (0.71 to 1.00$)$ & -15.2 & 0.15 & \\
\hline 150-225 min/week & 226 (201 to 254) & 203 (175 to 234$)$ & 63 & 0.90 (0.80 to 1.02$)$ & -9.7 & 0.36 & \\
\hline >225 min/week & 223 (190 to 261$)$ & 230 (197 to 269$)$ & 42 & 0.99 (0.85 to 1.15$)$ & -1.5 & 0.84 & \\
\hline
\end{tabular}

*Adherence was calculated as the mean minutes of exercise per week for the exercise group over the 52 weeks of the study.

†Blood samples from $n=159$ participants in the control group and $n=156$ participants in the exercise group were obtained. A further $n=1,12$ and 3 participants were removed from the SOD,

8-iso-PGF2 $\alpha$ and 8-OHdG analyses, respectively, as they were outliers or below the limit of detection.

†Ratio of geometric means at 12 months to geometric means at baseline, adjusted for the baseline oxidative stress biomarker or antioxidant activity level and age.

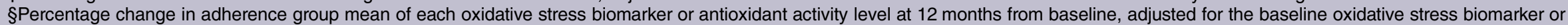
antioxidant activity level and age.

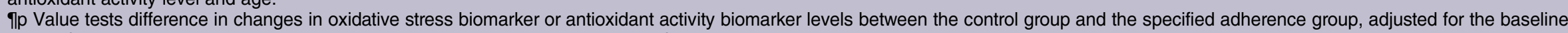
value of the oxidative stress biomarker or antioxidant activity level and age. A unified model, where the adherence group was treated as a categorical variable, was used to calculate the $p$ values, which correspond to $\beta$-coefficients for the other quintile groups, using the control group as the referent group.

${ }^{* *} p$ Value for trend represents a test of linear association between the adherence quintile and change in oxidative stress biomarker or antioxidant activity level from baseline to 12 months. This

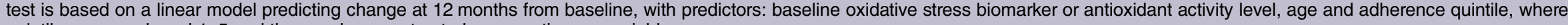
quintiles are numbered $1-5$ and these values are treated as a continuous variable.

8-iso-PGF2 $\alpha$, 8-isoprostaglandin F2 $\alpha$; 8-OHdg, 8-hydroxy-2'-deoxyguanosine; CAT, catalase; SOD, superoxide dismutase.

אqu 
increase; however, over time, this increase produces a compensation mechanism, by which adaptation occurs to higher levels of oxidative stress by upregulating the amount and efficiency of antioxidant enzymes. Increased ROS species have been attributed to a multitude of different cancers and other chronic diseases. ${ }^{13-15}$ Additionally, oxidative stress increases with increasing age $^{60}$ and there is evidence that postmenopausal women have higher levels of lipid peroxidation compared to premenopausal women. ${ }^{61}{ }^{62}$ Thus, their reduction due to physical activity could serve as a plausible mechanism of cancer prevention, although this effect was not observed in our trial.

The study population of the ALPHA Trial consisted of healthy, postmenopausal women. Healthier individuals may have lower levels of oxidative stress; hence, an exercise intervention may not have had a significant impact in reducing ROS or increasing antioxidant enzyme activity. This hypothesis is supported by the most comparable study of a year-long exercise intervention in postmenopausal women that showed only a modest improvement in urinary F2-isoprostane with exercise training. ${ }^{24}$ Nevertheless, we did not find any statistically significant interaction with baseline values of the oxidative stress markers.

The medium in which antioxidant enzyme activities were measured may have played a role in the lack of effect seen in this study. Most studies have shown an increase in antioxidant activity in erythrocytes $^{39} 42 \quad 46 \quad 5052555759$ or whole blood. ${ }^{44} 464950$ Studies using plasma measures of activity have shown inconsistent results, ${ }^{45} 4656$ with one study demonstrating a differential effect depending on whether enzyme activities were measured in plasma or in erythrocytes. ${ }^{46}$ Furthermore, plasma levels of antioxidant activity may not correlate with tissue levels. Similarly, in terms of oxidative stress biomarkers, urinary measures of F2-isprostanes have been found to show daily variability. ${ }^{63}$ In addition, concentrations of F2-isprostanes in urine are 20-50 times lower than in plasma and dependent on creatinine concentration, both suggesting that urine may be more sensitive to smaller changes. ${ }^{64}$ It is possible that antioxidant enzyme capacities and DNA damage biomarkers in plasma may not be as responsive to aerobic exercise training as those in erythrocytes, whole blood or urine.

Since the ALPHA Trial was a year-long intervention of $225 \mathrm{~min} /$ week of aerobic exercise, this time frame may be too long to observe an effect of the exercise intervention. Most trials that have shown increases in antioxidant enzyme capacity with exercise were much shorter in duration (8-24 weeks) ${ }^{45} \quad 4749515659$ and we hypothesise that without an increase in aerobic exercise volume or intensity, the exercise effect on oxidative stress biomarkers and antioxidant enzyme activity could have an adaptive effect over time. It is possible that an increase in antioxidant activity as a result of the intervention would have occurred within the first few weeks of the aerobic exercise training. Since oxidative stress is a balance between ROS and the antioxidant system, ${ }^{65}$ we hypothesise that this early increase in antioxidant enzyme activity could be matched by a decrease in ROS generation in response to the exercise training intervention such that, over time, the initial increase in antioxidant enzyme activity would begin to diminish and return to basal levels because of the decreased stimulus. Indeed, studies of prolonged aerobic exercise training do not always show an improvement in total antioxidant capacity ${ }^{66-68}$ The lack of effect on antioxidant enzyme capacity due to decreased ROS is most likely complemented by the decreased adiposity and $\mathrm{C}$ reactive protein (CRP) levels seen in the exercise group of the ALPHA Trial. ${ }^{11}{ }^{69}$ Adipose tissue has been shown to be a potent source of ROS, ${ }^{70}$ while increased CRP has been correlated with increased ROS. ${ }^{72}$

Overall, this study showed no effect of a year-long exercise intervention on these four markers of oxidative stress in healthy, postmenopausal women. While we did not find any statistically significant effects of aerobic exercise training on oxidative stress biomarkers in this study, based on the current literature and biological models, oxidative stress remains a plausible mechanism by which physical activity could influence breast cancer risk and further research is warranted.

\section{Author affiliations}

${ }^{1}$ Department of Cancer Epidemiology and Prevention Research, CancerControl Alberta, Alberta Health Services, Calgary, Alberta, Canada

${ }^{2}$ Departments of Oncology and Community Health Sciences, Cumming School of Medicine, University of Calgary, Calgary, Alberta, Canada

${ }^{3}$ Inter-University Laboratory of Human Movement Biology, Université Claude Bernard Lyon 1, University of Lyon, Villeurbanne, France

${ }^{4}$ Departments of Physiology and Pharmacology and Clinical Neurosciences, Hotchkiss Brain Institute, Cumming School of Medicine, University of Calgary, Calgary, Alberta, Canada

${ }^{5}$ Cancer Prevention Institute of California, Fremont, California, USA ${ }^{6}$ Departments of Pediatrics and Obstetrics and Gynecology, Faculty of Medicine, Dalhousie University, Halifax, Nova Scotia, Canada

${ }^{7}$ Faculty of Physical Education and Recreation, University of Alberta, Edmonton, Alberta, Canada

Acknowledgements The study set-up of the ALPHA trial was performed by Kim van der Hoek and Marla Orenstein. The Study Coordinators were Rosemary Crosby, Ame-Lia Tamburrini and Sarah MacLaughlin. Fitness Centre Managers were Ben Wilson, Lisa Workman and Diane Cook. Exercise Trainers were Shannon Hutchins, Kathy Traptow, Shannon Brown, Susan Daniel, Parissa Gillani, Stephanie Sanden, Karen Mackay and Sandra Olsen. Data preparation was conducted by Sandra Blitz and Sony Brar. Blood sample storage, maintenance and retrievals were carried out by the Alberta Cancer Research Biobank staff. Dr Scott Forbes conducted part of the laboratory assays for this study that were performed in the laboratory of Dr Katherine Wynne-Edwards at the University of Calgary.

Contributors CMF, KSC, SMC, CGW, VP and MJP took part in study concept, design and funding. CMF, KSC and CGW participated in data collection. VP, XW and MJP took part in laboratory analyses. QW, ES, DRB, CMF and KSC carried out data analysis. CMF, RJ, ES, DRB and KSC reviewed the manuscript. All authors reviewed and approved the final manuscript.

Funding The Alberta Physical Activity and Breast Cancer Prevention (ALPHA) Trial was funded by research grants from the Canadian Breast Cancer Research Alliance (number 13576 and number 017468), the Alberta Cancer Foundation (number 22170) and the ALPHA Ancillary Study was funded by 
the Canadian Institutes for Health Research (CIHR) (number MOP-130238). CMF holds a Health Senior Scholar Award from Alberta Innovates-Health Solutions (Al-HS) and is the Alberta Cancer Foundation Weekend to End Women's Cancers Breast Cancer Chair. VP was supported by the Institut Universitaire de France. SMC was supported by postdoctoral fellowships (AI-HS) and the CIHR. DRB was supported by a postdoctoral fellowship from Al-HS and a career award from the Canadian Cancer Society Research Institute. XW was supported by postdoctoral fellowships from the Hotchkiss Brain Institute, Al-HS and the CIHR. MJP holds the Brenda Strafford Foundation Chair in Alzheimer Research. KSC was supported by the Canada Research Chairs Programme.

\section{Competing interests None declared.}

Ethics approval Alberta Cancer Research Ethics Board (Alberta Cancer Board), the Conjoint Health Research Ethics Board (University of Calgary) and the Health Research Ethics Board (University of Alberta)

Provenance and peer review Not commissioned; externally peer reviewed.

Data sharing statement No additional data are available.

Open Access This is an Open Access article distributed in accordance with the Creative Commons Attribution Non Commercial (CC BY-NC 4.0) license, which permits others to distribute, remix, adapt, build upon this work noncommercially, and license their derivative works on different terms, provided the original work is properly cited and the use is non-commercial. See: http:// creativecommons.org/licenses/by-nc/4.0/

\section{REFERENCES}

1. Canadian Cancer Society's Advisory Committee on Cancer Statistics. Canadian Cancer Statistics 2015. Toronto, ON: Canadian Cancer Society, 2015.

2. Jemal A, Bray F, Center MM, et al. Global cancer statistics. CA Cancer J Clin 2011:61:69-90.

3. Holford TR, Cronin KA, Mariotto AB, et al. Changing patterns in breast cancer incidence trends. J Natl Cancer Inst Monogr 2006:19-25.

4. Neilson HK, Friedenreich CM, Brockton NT, et al. Physical activity and postmenopausal breast cancer: proposed biologic mechanisms and areas for future research. Cancer Epidemiol Biomarkers Prev 2009;18:11-27.

5. Foster-Schubert KE, Alfano CM, Duggan CR, et al. Effect of diet and exercise, alone or combined, on weight and body composition in overweight-to-obese postmenopausal women. Obesity (Silver Spring) 2012;20:1628-38.

6. Friedenreich CM, Woolcott CG, McTiernan A, et al. Alberta physical activity and breast cancer prevention trial: sex hormone changes in a year-long exercise intervention among postmenopausal women. J Clin Oncol 2010;28:1458-66.

7. McTiernan A, Tworoger SS, Ulrich CM, et al. Effect of exercise on serum estrogens in postmenopausal women: a 12-month randomized clinical trial. Cancer Res 2004;64:2923-8.

8. Monninkhof EM, Velthuis MJ, Peeters PH, et al. Effect of exercise on postmenopausal sex hormone levels and role of body fat: a randomized controlled trial. J Clin Oncol 2009;27:4492-9.

9. Friedenreich CM, MacLaughlin S, Neilson HK, et al. Study Design and Methods for the Breast Cancer and Exercise Trial in Alberta (BETA). BMC Cancer 2014;14:919.

10. Campbell PT, Campbell KL, Wener $\mathrm{MH}$, et al. A yearlong exercise intervention decreases CRP among obese postmenopausal women. Med Sci Sports Exerc 2009;41:1533-9.

11. Friedenreich CM, Neilson HK, Woolcott CG, et al. Inflammatory marker changes in a year-long randomized exercise intervention trial among postmenopausal women. Cancer Prev Res 2012;5: 98-108.

12. Frank LL, Sorensen BE, Yasui $Y$, et al. Effects of exercise on metabolic risk variables in overweight postmenopausal women: a randomized clinical trial. Obes Res 2005;13:615-25.

13. Nourazarian AR, Kangari $P$, Salmaninejad A. Roles of oxidative stress in the development and progression of breast cancer. Asian Pac J Cancer Prev 2014;15:4745-51.

14. Kruk J. Overweight, obesity, oxidative stress and the risk of breast cancer. Asian Pac J Cancer Prev 2014;15:9579-86.

15. Toyokuni S, Okamoto K, Yodoi J, et al. Persistent oxidative stress in cancer. FEBS Lett 1995;358:1-3.
16. Radak Z, Marton O, Nagy E, et al. The complex role of physical exercise and reactive oxygen species on brain. J Sport Health Sci 2013;2:87-93.

17. Behrend L, Henderson G, Zwacka RM. Reactive oxygen species in oncogenic transformation. Biochem Soc Trans 2003;31:1441-4.

18. Semenza GL. HIF-1: using two hands to flip the angiogenic switch Cancer Metastasis Rev 2000;19:59-65.

19. Goodman M, Bostick RM, Dash C, et al. A summary measure of pro- and anti-oxidant exposures and risk of incident, sporadic, colorectal adenomas. Cancer Causes Control 2008;19:1051-64.

20. Klaunig JE, Kamendulis LM. The role of oxidative stress in carcinogenesis. Annu Rev Pharmacol Toxicol 2004;44:239-67.

21. Leaf DA, Kleinman MT, Hamilton $M$, et al. The exercise-induced oxidative stress paradox: the effects of physical exercise training Am J Med Sci 1999;317:295-300.

22. Melikoglu MA, Kaldirimci M, Katkat D, et al. The effect of regular long term training on antioxidant enzymatic activities. J Sports Med Phys Fitness 2008;48:388-90.

23. Pialoux V, Brown AD, Leigh R, et al. Effect of cardiorespiratory fitness on vascular regulation and oxidative stress in postmenopausal women. Hypertension 2009;54:1014-20.

24. Campbell PT, Gross MD, Potter JD, et al. Effect of exercise on oxidative stress: a 12-month randomized, controlled trial. Med Sci Sports Exerc 2010;42:1448-53.

25. Radak Z, Chung HY, Goto S. Systemic adaptation to oxidative challenge induced by regular exercise. Free Radic Biol Med 2008;44:153-9.

26. Ambrosone CB. Oxidants and antioxidants in breast cancer. Antioxid Redox Signal 2000;2:903-17.

27. Ji LL. Exercise and oxidative stress: role of the cellular antioxidant systems. Exerc Sport Sci Rev 1995;23:135-66.

28. Soares JP, Silva AM, Oliveira MM, et al. Effects of combined physical exercise training on DNA damage and repair capacity: role of oxidative stress changes. Age (Dordr) 2015;37:9799.

29. Loft S, Møller P, Cooke MS, et al. Antioxidant vitamins and cancer risk: is oxidative damage to DNA a relevant biomarker? Eur J Nutr 2008;47(Suppl 2):19-28.

30. Valavanidis A, Vlachogianni T, Fiotakis C. 8-hydroxy-2' -deoxyguanosine (8-OHdG): a critical biomarker of oxidative stress and carcinogenesis. J Environ Sci Health C Environ Carcinog Ecotoxicol Rev 2009;27:120-39.

31. Rossner P Jr, Gammon MD, Terry MB, et al. Relationship between urinary 15-F2t-isoprostane and 8-oxodeoxyguanosine levels and breast cancer risk. Cancer Epidemiol Biomarkers Prev 2006;15:639-44.

32. Chiou CC, Chang PY, Chan EC, et al. Urinary 8-hydroxydeoxyguanosine and its analogs as DNA marker of oxidative stress: development of an ELISA and measurement in both bladder and prostate cancers. Clin Chim Acta 2003;334:87-94.

33. Chirico EN, Martin C, Faës C, et al. Exercise training blunts oxidative stress in sickle cell trait carriers. J Appl Physiol (1985) 2012;112:1445-53.

34. Johansson LH, Borg LA. A spectrophotometric method for determination of catalase activity in small tissue samples. Anal Biochem 1988;174:331-6.

35. Beauchamp C, Fridovich I. Superoxide dismutase: improved assays and an assay applicable to acrylamide gels. Anal Biochem 1971;44:276-87.

36. Oberley L, Spitz D. Nitroblue tetrazolium. Handbook of methods for oxygen radical research. Boca Raton: CDC Press, 1985.

37. Warburton DE, Katzmarzyk PT, Rhodes RE, et al. Evidenceinformed physical activity guidelines for Canadian adults. Can J Public Health 2007;98(Suppl 2):S16-68.

38. Kraemer HC, Wilson GT, Fairburn CG, et al. Mediators and moderators of treatment effects in randomized clinical trials. Arch Gen Psychiatry 2002;59:877-83.

39. Bouzid MA, Hammouda O, Matran R, et al. Influence of physical fitness on antioxidant activity and malondialdehyde level in healthy older adults. Appl Physiol Nutr Metab 2015;40:582-9.

40. Farinha JB, De Carvalho NR, Steckling FM, et al. An active lifestyle induces positive antioxidant enzyme modulation in peripheral blood mononuclear cells of overweight/obese postmenopausal women. Life Sci 2015;121:152-7.

41. Fraile-Bermúdez AB, Kortajarena M, Zarrazquin I, et al. Relationship between physical activity and markers of oxidative stress in independent community-living elderly individuals. Exp Gerontol 2015;70:26-31

42. Rowiński R, Kozakiewicz M, Kedziora-Kornatowska K, et al. Markers of oxidative stress and erythrocyte antioxidant enzyme activity in older men and women with differing physical activity. Exp Gerontol 2013;48:1141-6. 
43. Shanely RA, Nieman DC, Henson DA, et al. Inflammation and oxidative stress are lower in physically fit and active adults. Scand J Med Sci Sports 2013;23:215-23.

44. Cardoso AM, Bagatini MD, Roth MA, et al. Acute effects of resistance exercise and intermittent intense aerobic exercise on blood cell count and oxidative stress in trained middle-aged women. Braz J Med Biol Res 2012:45:1172-82.

45. Takahashi M, Miyashita M, Kawanishi N, et al. Low-volume exercise training attenuates oxidative stress and neutrophils activation in older adults. Eur J Appl Physiol 2013;113:1117-26.

46. Palasuwan A, Suksom D, Margaritis I, et al. Effects of tai chi training on antioxidant capacity in pre- and postmenopausal women. J Ageing Res 2011;2011:234696.

47. Devries MC, Hamadeh MJ, Glover AW, et al. Endurance training without weight loss lowers systemic, but not muscle, oxidative stress with no effect on inflammation in lean and obese women. Free Radic Biol Med 2008;45:503-11.

48. Schmitz KH, Warren M, Rundle AG, et al. Exercise effect on oxidative stress is independent of change in estrogen metabolism. Cancer Epidemiol Biomarkers Prev 2008;17:220-3.

49. Elosua R, Molina L, Fito M, et al. Response of oxidative stress biomarkers to a 16 -week aerobic physical activity program, and to acute physical activity, in healthy young men and women. Atherosclerosis 2003;167:327-34.

50. Covas MI, Elosua R, Fitó M, et al. Relationship between physical activity and oxidative stress biomarkers in women. Med Sci Sports Exerc 2002;34:814-19.

51. Shin $Y A$, Lee $J H$, Song $W$, et al. Exercise training improves the antioxidant enzyme activity with no changes of telomere length. Mech Ageing Dev 2008;129:254-60.

52. Rosado-Pérez J, Ortiz R, Santiago-Osorio E, et al. Effect of Tai Chi versus walking on oxidative stress in Mexican older adults. Oxid Med Cell Longev 2013;2013:298590.

53. Arikawa AY, Thomas W, Gross M, et al. Aerobic training reduces systemic oxidative stress in young women with elevated levels of F2-isoprostanes. Contemp Clin Trials 2013;34:212-17.

54. Smith DT, Carr LJ, Dorozynski C, et al. Internet-delivered lifestyle physical activity intervention: limited inflammation and antioxidant capacity efficacy in overweight adults. J Appl Physiol (1985) 2009;106:49-56.

55. Bartfay W, Bartfay E. A case-control study examining the effects of active versus sedentary lifestyles on measures of body iron burden and oxidative stress in postmenopausal women. Biol Res Nurs 2014; 16:38-45.

56. Merino J, Ferré R, Girona J, et al. Even low physical activity levels improve vascular function in overweight and obese postmenopausal women. Menopause 2013;20:1036-42.

57. Karolkiewicz J, Michalak E, Pospieszna B, et al. Response of oxidative stress markers and antioxidant parameters to an 8-week aerobic physical activity program in healthy, postmenopausal women. Arch Gerontol Geriatr 2009;49:e67-71.

58. Attipoe S, Park JY, Fenty N, et al. Oxidative stress levels are reduced in postmenopausal women with exercise training regardless of hormone replacement therapy status. J Women Ageing 2008;20:31-45

59. Hernández R, Mahedero G, Caballero MJ, et al. Effects of physical exercise in pre-and postmenopausal women on lipid peroxidation and antioxidant systems. Endocr Res 1999;25:153-61.

60. Judge S, Leeuwenburgh $\mathrm{C}$. Cardiac mitochondrial bioenergetics, oxidative stress, and ageing. Am J Physiol, Cell Physiol 2007;292: C1983-92.

61. Castelao JE, Gago-Dominguez M. Risk factors for cardiovascular disease in women: relationship to lipid peroxidation and oxidative stress. Med Hypotheses 2008;71:39-44.

62. Gago-Dominguez M, Castelao JE, Pike MC, et al. Role of lipid peroxidation in the epidemiology and prevention of breast cancer Cancer Epidemiol Biomarkers Prev 2005;14:2829-39.

63. Helmersson J, Basu S. F(2)-isoprostane and prostaglandin $\mathrm{F}(2$ alpha) metabolite excretion rate and day to day variation in healthy humans. Prostaglandins Leukot Essent Fatty Acids 2001;65:99-102.

64. Sircar D, Subbaiah PV. Isoprostane measurement in plasma and urine by liquid chromatography-mass spectrometry with one-step sample preparation. Clin Chem 2007;53:251-8.

65. Finaud J, Lac G, Filaire E. Oxidative stress: relationship with exercise and training. Sports Med 2006;36:327-58.

66. Neubauer O, König D, Kern N, et al. No indications of persistent oxidative stress in response to an ironman triathlon. Med Sci Sports Exerc 2008;40:2119-28.

67. Powers SK, Jackson MJ. Exercise-induced oxidative stress: cellular mechanisms and impact on muscle force production. Physiol Rev 2008;88:1243-76.

68. Powers SK, Ji LL, Leeuwenburgh C. Exercise training-induced alterations in skeletal muscle antioxidant capacity: a brief review. Med Sci Sports Exerc 1999;31:987-97.

69. Friedenreich CM, Woolcott CG, McTiernan A, et al. Adiposity changes after a 1-year aerobic exercise intervention among postmenopausal women: a randomized controlled trial. Int $\mathrm{J}$ Obes (Lond) 2011;35:427-35

70. Keaney JF Jr, Larson MG, Vasan RS, et al. Obesity and systemic oxidative stress: clinical correlates of oxidative stress in the Framingham Study. Arterioscler Thromb Vasc Biol 2003;23:434-9.

71. Furukawa S, Fujita T, Shimabukuro M, et al. Increased oxidative stress in obesity and its impact on metabolic syndrome. J Clin Invest 2004;114:1752-61.

72. Cottone $\mathrm{S}$, Mulè $\mathrm{G}$, Nardi $\mathrm{E}$, et al. Relation of $\mathrm{C}$ reactive protein to oxidative stress and to endothelial activation in essential hypertension. Am J Hypertens 2006;19:313-8. 